\section{Comentarios al artículo: Una mirada al origen, funcionamiento y desafíos del nuevo sistema de trasplantes chileno}

\section{Comments to the article: A peek to the origin, functioning and challenges of the new Chilean transplantation system}

\section{Sr. Editor:}

He leído con interés el artículo especial "Una mirada al origen, funcionamiento y desafíos del nuevo sistema de donación y trasplantes chileno"'. Desearía comentar ciertos aspectos y efectuar algunas precisiones.

Señalan los autores que: "En Chile, las cifras de donaciones, aunque históricamente bajas, han ido aumentando gracias a las reformas legales que instituyeron el Sistema del Consentimiento presunto que ha permitido que el 2017 pase a la historia como el mejor año para la donación y trasplante[...]".

Es difícil sostener lo señalado, pues si analizamos el promedio de la tasa de donación efectiva para el período 2002-2009, pre ley del Consentimiento presunto de 2010 , veremos que esta cifra es de 8,25 donantes por millón de habitantes(pmh), sin duda baja, pero superior a la tasa promedio para el período 2010-2017, que es de 7,42 donantes $\mathrm{pmh}^{2}$. También, es difícil sostener que fueron las reformas legales las que permitieron que el año 2017 sea histórico, soslayando la importancia que tuvieron las campañas comunicacionales del Ministerio de Salud junto a Defensa, Justicia, ANATEL, etc. llamando a la solidaridad y donación.

En "Algunas notas sobre el nuevo sistema de trasplantes chileno", los autores señalan: "Destaca el modelo de Consentimiento presunto incorporado en la ley 20.413 de 2010 con el fin de frenar el descenso que, desde 2006 experimentaron las cifras de donación. El efecto de la ley fue, en un principio, desastroso, pues erróneamente se permitía manifestar voluntad de no ser donante al momento de renovar el carnet de identidad o de conducción, es decir, con poca o ninguna reflexión de por medio[...]". La ley 19.451 de 1996, en su articulo $9^{\circ}$, introdujo elementos que permiten conocer en vida la voluntad del difunto, respecto de la donación de órganos: declaración ante Notario, al ingresar a un hospital o clínica, al solicitar o renovar la licencia para conducir o bien para obtener o renovar la cédula de identidad. En resumen, desde 1996 acudíamos a estos lugares a expresar nuestra voluntad de ser o no donantes y desde el 2010 al 2012, lo hicimos, casi, a los mismos lugares, pero ahora a expresar que no somos donantes. Así, nos parece que "el efecto desastroso inicial de la ley", no se debió al error de permitir a los ciudadanos manifestar su voluntad de no donar, que ya poseían, sino que es consecuencia directa del reemplazo del criterio del Consentimiento expreso para la donación de órganos, por el criterio del Consentimiento presunto. Al parecer, la sociedad valora la donación de órganos como un acto altruista y no como una obligación legal.

Señalan los autores que: "la ley 20.673 de 2013 introdujo un criterio ético que permitiese garantizar una decisión informada y reflexiva sobre la decisión de no donar, llamado "principio de reciprocidad[...]". Sabemos que las normas jurídicas no cambian la cultura de un pueblo, pero la educación sí. Por otra parte, el "principio de reciprocidad", al que aluden los autores, no tiene aplicabilidad real, pues es casi imposible, por no decir imposible, que existan dos pacientes en igualdad de condiciones para recibir un órgano y el único factor que los discrimine, sea si está o no inscrito en el Registro Nacional de No Donantes.

$\mathrm{Al}$ inicio del artículo, los autores señalan: "Persisten los problemas derivados de la indebida participación de la familia en las decisiones últimas sobre donación". Más adelante, dicen estar de acuerdo con la decisión de la Contraloria que cuestionó que los equipos de procura de órganos, de algunos hospitales, hayan solicitado la donación a familiares de pacientes que aparecían inscritos en el Registro de No Donantes. Es habitual que la práctica clínica nos muestre una realidad que difiere completamente de la visión que se tiene, de esta materia, desde el mundo del Derecho, ya que la extracción de órganos en personas fallecidas, no se realiza sin el consentimiento de los familiares ${ }^{3}$, no sólo en Chile, sino en numerosos países donde impera el criterio jurídico del Consentimiento presunto, incluido el modelo español, cuyo éxito destacan los autores. Establecer una relación médico/paciente/familia, es una de las herramientas más importantes para un tratamiento exitoso y para ello, el equipo médico adquiere durante su formación, las habilidades y destrezas para lograr este objetivo. $\mathrm{Si}$ el Coordinador de trasplante del hospital o su equipo fracturan esta relación, al no incorporar a la familia en el proceso de donación/trasplante, la desconfianza en los profesionales y en el sistema sanitario será máxima y obviamente, su transparencia nula, sin considerar la sensación familiar de extrema vulnerabilidad y abandono. Por otra parte, desde el punto de vista jurídico, el artículo $2^{\circ}$ bis de la ley 20.673 señala que, en caso de duda fundada, respecto de la calidad de donante del fallecido, debe consultarse a los familiares con el objeto de aclarar su última voluntad, sin distinguir si éste se encuentra inscrito o no en el Registro de No Donantes. Finalmente debo recordar que, la solicitud de reconsideración del informe final No 857 de 2017 de la Contraloría, en relación con la intervención familiar en el procuramiento y trasplante de órganos de personas fallecidas, fue acogida favorablemente con el № 17.656 de fecha 13 de agosto 2018, por el Contralor, Sr. Jorge Bermudez, modificando los criterios contenidos en dicho informe. 
En la sección Conclusiones, los autores señalan que: "En su momento, manifestamos en el Congreso Nacional que la modificación de la ley debía necesariamente invalidar las declaraciones de voluntad expresadas sin mayor reflexión[...]”. Al respecto debo consignar lo dicho, en el Congreso Nacional, el 11/09/2012, por el Prof. de Derecho Civil Mauricio Tapia Rodríguez: "La ley no puede tener efecto retroactivo y los vicios del consentimiento, solo pueden ser declarados por un tribunal y no mediante una ley que desdiga la voluntad de las personas."Agregando que: "Las leyes tienen que ir unidas a una política pública de apoyo a la promoción de la donación de órganos, pues, sin ése soporte, son solo instrumentos de carácter didáctico".

\section{Dr. Sergio Thambo Becker ${ }^{1}$} ${ }^{1}$ Nefrólogo

Los autores aludidos ofrecieron la siguiente réplica:

Una mirada al origen, funcionamiento y desafíos del nuevo sistema de trasplantes chileno. Réplica

\section{A peek to the origin, functioning and challenges of the new Chilean transplantation system. Reply}

\section{Señor Editor:}

Los dilemas morales asociados a la donación y trasplante de órganos trascienden con mucho la mera práctica médica. Las controversias sobre la donación, en el debate contemporáneo, generan disyuntivas jurídicas, filosóficas, sociológicas e incluso religiosas que requiere de nuevas voces y actores capaces de aportar en la búsqueda de soluciones a los principales problemas: la escasez y la justa adjudicación. En esta línea, valoramos el interés del doctor Thambo hacia nuestra investigación y aprovecharemos esta oportunidad para aclarar algunos puntos importantes.

Son múltiples los factores que explican las magras cifras de donación de órganos en nuestro país: la baja disponibilidad de potenciales donantes, las negativas familiares, la escasa inversión del Estado en infraestructura para trasplante, entre varios otros. Que no se hayan producido alzas significativas que acompañen los cambios legislativos registrados en los últimos años se debe-si se quiere ser riguroso- en que la práctica médica $y$ los errores administrativos han desvirtuado y anulado el espiritu de las reformas legales. Baste recordar que, al momento de hacer efectiva la nueva normativa, se permitió manifestar voluntad por una vía claramente inadecuada para ello: al momento de renovar el carnet de conducir o el de identidad. De esta forma, millones

\section{Referencias}

1. Zúñiga-Fajuri A, Merino MP, Urtubia M. Una mirada al origen, funcionamiento y desafíos del nuevo sistema de donación y trasplantes chileno. Rev Med Chile 2018; 146: 780-5.

2. Ministerio de Salud de Chile. Datos Donantes Organos y Trasplantes. www.minsal.cl/wp-content/uploads/2018/.../ Datos-Pagina-Enero-Diciembre 2017.pdf [Consultado el 25 de septiembre de 2018].

3. Hernández VL. El Consentimiento presunto en la legislación sobre trasplante de órganos y el derecho a la información de los familiares. Revista Cesco de Derecho de Consumo. 2014; (12): 181-4. Disponible en: http://www.revista.uclm. es/index.php/cesco [Consultado el 15 de octubre de 2018].

Correspondencia a:

Dr. Sergio Thambo Becker

A. Vespucio Norte 280 Las Condes. Santiago, Chile.

de personas, sin información ni reflexión alguna, optaron por negar su voluntad para ser donantes de órganos, haciendo ineficaz, en su aplicación, la reforma legal.

La administración está tan conciente de su error que hoy está en trámite un Proyecto de Ley que pretende anular en la práctica esas declaraciones viciadas por la vía de exigir su ratificación ante la notaría. Además, el proyecto dispone que "Será obligación del médico tratante notificar a la respectiva Unidad de Coordinación de Procuramiento de Órganos y Tejidos, acerca del estado de muerte encefálica del paciente. El médico que incumpla esta obligación será responsable administrativa o civilmente, según fuera el caso"1.

Por cierto que no parece razonable, a estas alturas, negar lo que las cifras porfiadamente han demostrado: la idoneidad del modelo de consentimiento presunto para aumentar la donación de órganos. Es la razón por la que los países con mayores tasas de donación en el mundo han adoptado, sin excepción, este modelo y la razón, también, por la que lo han hecho recientemente México, Colombia y Argentina. Y es que el modelo altruista, en el que se sustentaban los sistemas tradicionales de donación y trasplante, habría fracasado. Los datos muestran que en Chile existe gran ignorancia en la población sobre qué significa "ser donante" fundamentalmente porque se desconfía del sistema y de los médicos a quienes se percibe como sujetos capaces de "dejar morir" a un paciente a fin de hacer uso de sus órganos ${ }^{2}$.

Cuando las reformas legales, en materia de donación de órganos, se realizan correctamente, son exitosas y el reciente caso de la Ley Justina en Argentina es prueba de ello. Gracias a la Ley -vigente desde agosto de 2018- la cantidad de donantes de órganos se incrementó exponencialmente. Aun cuando sólo comenzó 
a regir a mediados de año, durante 2018 se realizaron 701 donaciones de órganos, permitiendo trasplantar a 1.681 personas, lo que significó una marca histórica de donantes y trasplantes de órganos en el país, según los datos del Incucai ${ }^{3}$.

¿Cuál es la diferencia con Chile? ¿Por qué allá sí fue exitosa la reforma?

El presidente del Incucai, Alberto Maceira, lo explica muy bien: el éxito es debido a la nueva ley de trasplante de órganos, tejidos y células "y a que $e l$ sistema de salud-los profesionales de la salud-supieron interpretar el alma de la norma"4. En efecto, desde la Ley Justina la oposición de las familias a donar bajó del $40 \%$ al $17 \%$, fundamentalmente porque el personal de salud-médicos y enfermeros-cumplieron con la tarea de aplicar la normativa de consentimiento presunto y su regla que dispone que los familiares del fallecido ya no son los encargados de tomar esa decisión. Así, parece que lo que resulta crucial para el éxito de cualquier reforma es que los funcionarios sanitarios hagan cumplir la ley, pues si ella (como lo hace la ley chilena) exige que se respete la voluntad del donante pero los médicos siguen admitiendo la negativa familiar, las tasas de donación no pueden mejorar ${ }^{5}$.

$\mathrm{Al}$ contrario de lo que opina el doctor Thambo, creemos que el derecho es un factor de cambio social fundamental. El sólo hecho de que una ley declare que lo que antes era legítimo, ya no lo es, puede significar una inmensa transformación social, como ocurrió cuando se aprobó la ley de violencia intrafamiliar (ya no estaba permitido golpear a la esposa y a los hijos), cuando se despenalizó la sodomía consentida entre adultos (la homosexualidad dejó de ser un delito), cuando se derogó la normativa que discriminaba a los niños entre "legítimos" e "ilegítimos" etc. En el espacio del cuidado sanitario, los cambios sociales que han significado, por ejemplo, la Ley del Tabaco, la Ley de Etiquetado de los Alimentos y la Ley de Despenalización del Aborto, han sido enormes ${ }^{6}$.

Chile es mejor gracias a estas leyes que, de manera gradual, logran cambiar conductas dañinas, reconocer derechos y concientizar a la población sobre la im- portancia de actuar responsablemente. Para lograr la efectividad de una ley no sólo se requiere contar con políticas públicas bien diseñadas sino que, más importantes aún, es lograr el compromiso de los profesionales de la salud. Ninguna reforma a la ley de donación podrá nunca tener éxito si quienes tienen el deber de aplicarla, finalmente no lo hacen.

\section{Alejandra Zúñiga-Fajuri, María del Pilar Merino ${ }^{2}$, Mack Urtubia ${ }^{2}$ ${ }^{1}$ Doctora en derecho. Profesora titular de la Universidad de Valparaíso, Chile. ${ }^{2}$ Universidad de Valparaíso, Chile.}

\section{Referencias}

1. https://www.camara.cl/pley/pley_detalle.aspx?prmID=12413 \&prmBoletin=11893-11.

2. Zúñiga-Fajuri. Increasing organ donation by presumed consent and allocation priority: Chile. Bulletin of the World Health Organization 2015; 93: 199-202. https://www.ncbi. nlm.nih.gov/pmc/articles/PMC4339830/

3. Instituto Nacional Central Único Coordinador de Ablación e Implante de la República Argentina. https://www.argentina. gob.ar/salud/incucai.

4. https://infocielo.com/nota/100100/aseguran_que_gracias_a_la_ley_justina_en_2018_mas_de_mil_personas_pudieron_ser_trasplantadas/

5. Zúñiga-Fajuri A. Organ Donation and Family veto. Bioethical Reasons for a Change.Revista de Nefrología, Diálisis y Trasplante. Diciembre 2018. https://www.revistarenal.org. ar/index.php/rndt/article/view/375/482.

6. https://www.thelancet.com/journals/langlo/issue/vol5no4/ PIIS2214-109X(17)X0004-1.

Correspondencia a:

Alejandra Zúñiga

Universidad de Valparaíso, Errázuriz 2120 - Valparaíso, Chile.

Postal Code: 2362736

alejandra.zuniga@uv.cl 